\title{
ELECTRICAL TOMOGRAPHY AND VLF METHODS CONTRIBUTION TO UNDERGROUND WASTEWATER PIPE CONSTRUCTION
}

\author{
Vargemezis G. ${ }^{1}$, Gerolymatos E. ${ }^{2}$, and Aggelopoulos A. ${ }^{2}$

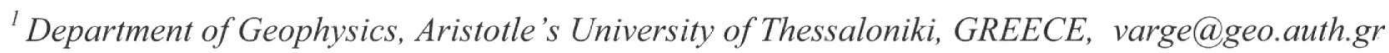 \\ ${ }^{2}$ Athens Water Supply and Sewerage Company (EYDAP SA), gerolymatos@eyath.gr, \\ angelopoulos@eyath.gr
}

\begin{abstract}
In the area of municipality of Kropia (Attica, Athens) the construction of a tunnel for the transportation of treated wastewater has been decided. The length of the tunnel is approximately $1400 \mathrm{~m}$ and it is designed to cross an area at a depth of maximum 100 meters. Geological and tectonic mapping showed the existence of limestone and fault systems zones that are crossing the geological formations. Thus, geophysical survey has been designed in order to provide information about the geological and tectonic status at the proposed area.

The application of electrical tomography has been designed in addition with VLF electromagnetic method. The first one was expected to show the geological cross section at the axis designed while the VLF method could provide more detailed information about the fault structures zones at the area.

Results of the geophysical survey showed lateral changes of the mechanical behaviour of the limestone. In parallel, fault zones that are crossing the axis have been mapped.

Considering that engineers need to know the nature of probable problems that they have to deal with, geophysical investigation can provide useful information in a low cost and quick application and contribute to the best decision as concern the final positioning of the tunnel and the penetrating method.
\end{abstract}

Key words: Tomography, VLF, tunnel.

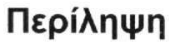

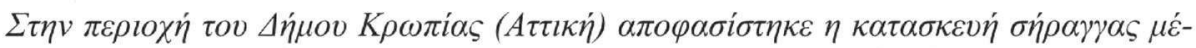

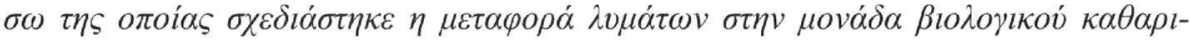

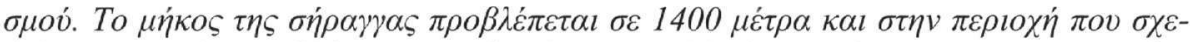

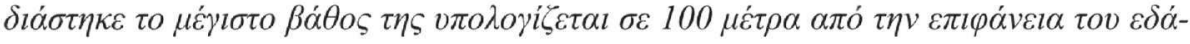

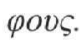

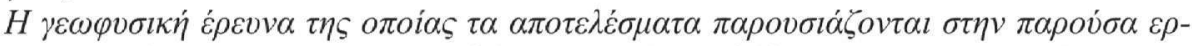

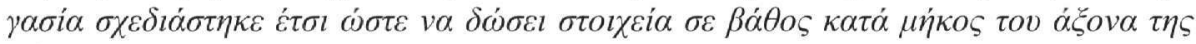

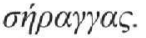

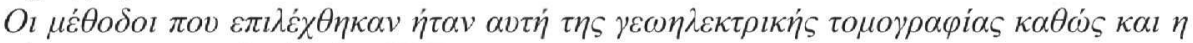

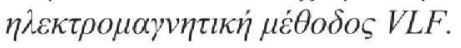




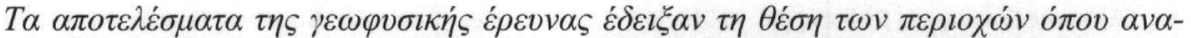

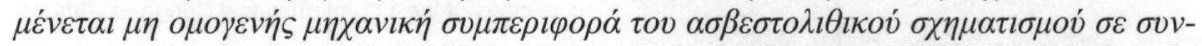

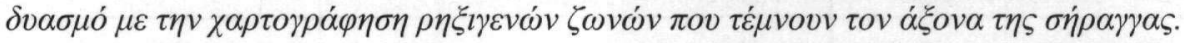

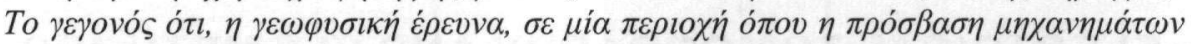

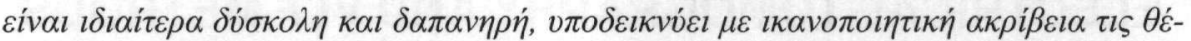

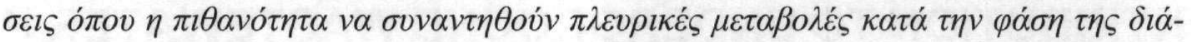

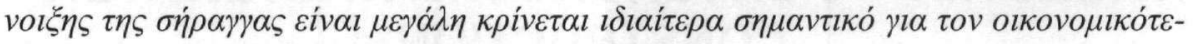

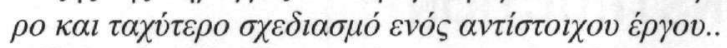

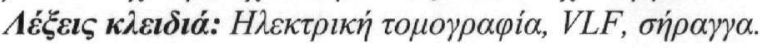

\section{Introduction}

Geophysical methods are widely used in contribution to geotechnical problems (Sultan et al. 2004, Roth et al. 2002, Rey et al. 2005, Cosenza et al. 2006, Cardarelli et al. 2003, Friedel et al. 2006). In many cases engineers have to deal with complex geological structures where the mechanical behaviour of rocks that need to be penetrated shows lateral changes that could be a serious problem for the construction. Underground water and faults that could be found during drilling pose also serious problems on the safety and stability of the construction.

Accurate positioning of tunnels having large dimensions that are scheduled to be constructed in a great depth is considered to be more difficult to be achieved since the procedure of drilling has particular difficulties as concern the safety of equipment and labour. Thus, accurate study of the underground in areas where deep tunnels are to be constructed is of a great importance.

It is well known that geophysical investigation is very effective since usually it is quicker and cheaper in comparison with drilling procedure. It can give information that allows to constructors to the best positioning of the construction and it also allows scheduling the drilling program in the best cost effective way.

In the area where the tunnel that will host the pipe of the wastewater in Kropia will be constructed, the access on the surface is very difficult because of the topographic relief.

Thus, the geoelectrical tomography and VLF surveys have been applied in order to examine the geological structure and any probable faulting along the axis of the microtunnel.
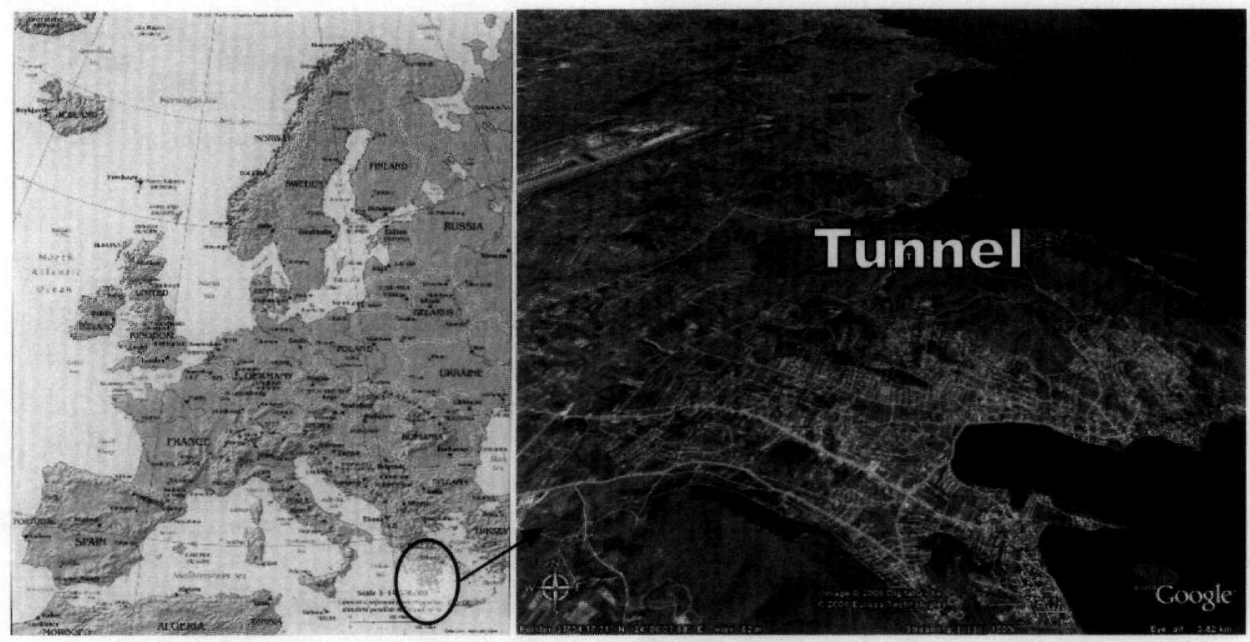

Figure 1 - Location of the tunnel 


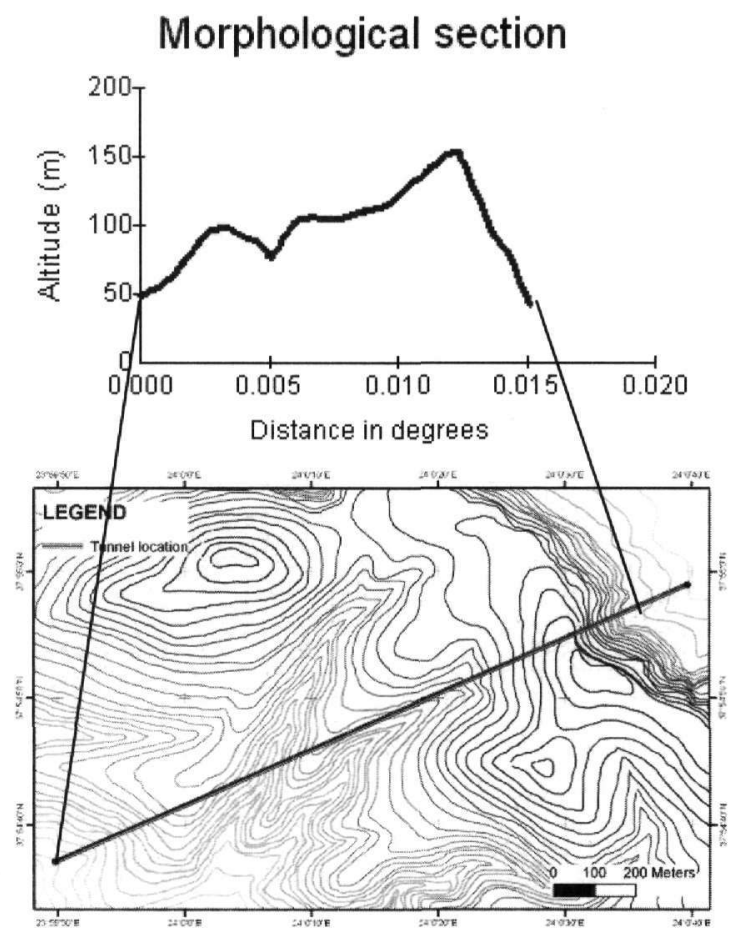

Figure 2 - Morphological section of the surface above tunnel

\section{General information of the area surveyed}

\subsection{Location-Topography}

The area is located east of the airport of Athens, Greece, and at the south of the Vravronas bay (Fig. 1).

The tunnel is scheduled to be constructed at the mean altitude of 45 meters from the sea level. The morphological section at the surface is given in Fig. 2.

\subsection{Geological setting of the area}

The geological map of the area has been constructed on the scale of 1:5000 (Fig. 3).

As someone can see on the map the tunnel is schedule to be constructed in the formation of limestone.

Fault zones having NW-SE and NE-SW directions are crossing the area and they are under further examination of the geophysical survey.

\section{Methods applied}

\subsection{Electrical tomography}

The parameters of the tomography have been adapted to the best investigation of the area. The electrode array of pole-dipole has been selected in order to reduce as much as possible the signal to noise ratio, since pole dipole array is considered to be the most stable among others commonly used (dipole-dipole, wenner-schlumberger). 


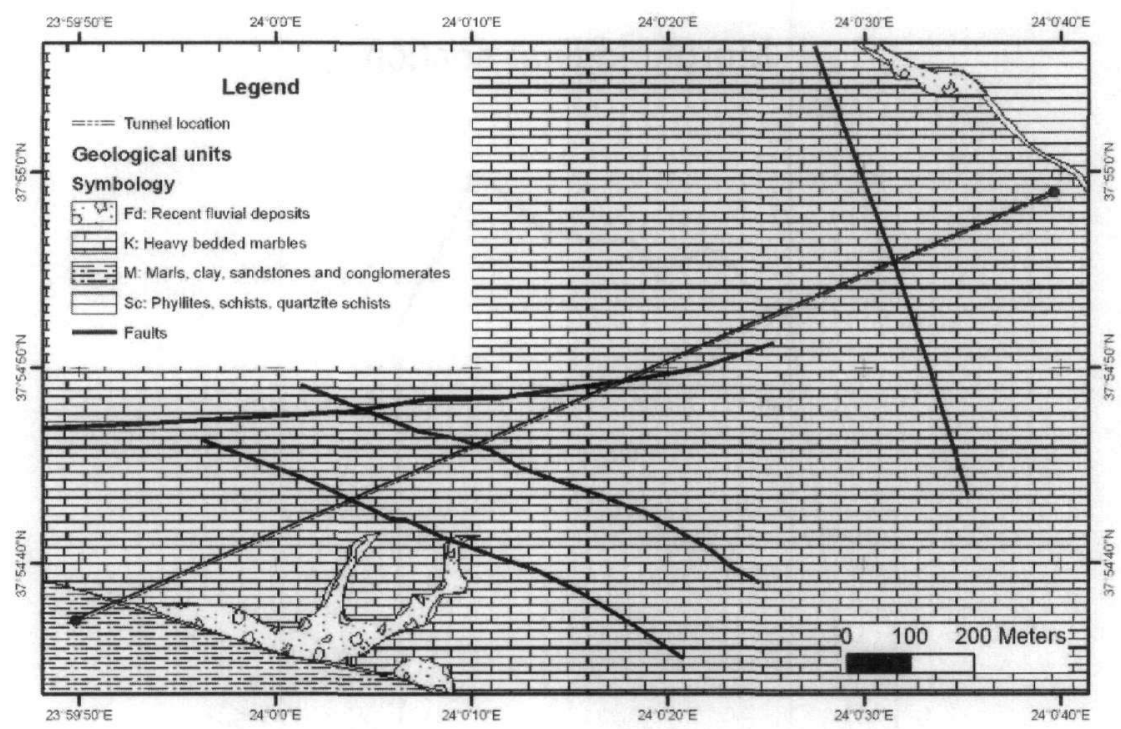

Figure 3 - Geological map of the area

The SYSCAL instrument has been used for the electrical tomography.

Since the desired depth of investigation was set to 80 meters the parameters were:

- Electrode separation (a): $6 \mathrm{~m}$

- Maximum distance between current electrode and potential dipole was set to $n * a, n * 2 a$ and $n * 3 a$ where maximum value of $n$ was 8 .

The expected depth of the array described with these parameters is close to 95 meters and in the initial tomography 690 measurements of the apparent resistivity have been measured (Fig. 4a).
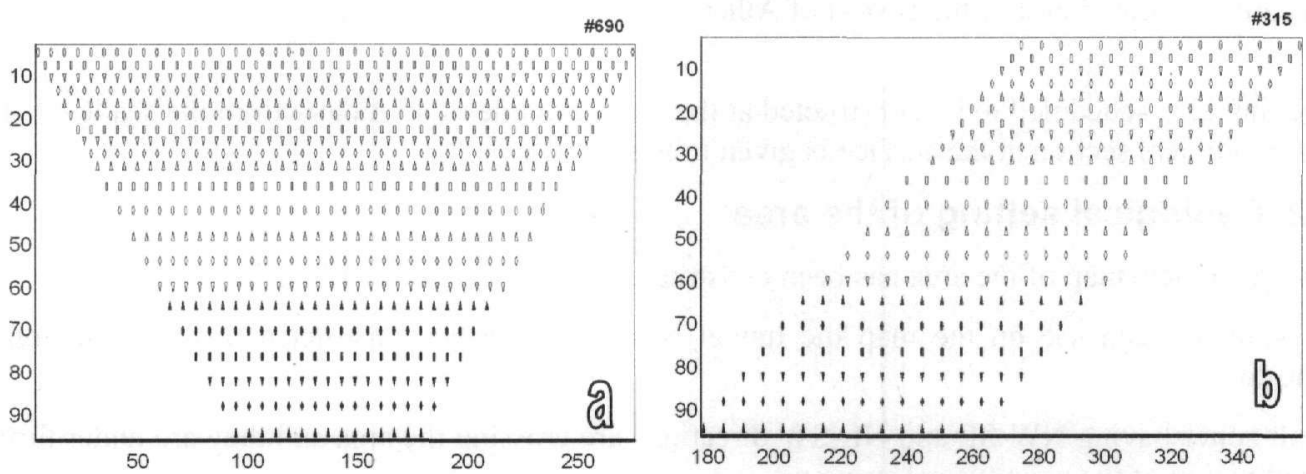

Figure 4 - Sketch of the designed initial tomography (a). Roll along tomography (b)

Since we were allowed to use the maximum of 48 electrodes, the length of the initial tomography was 282 meters (47 spaces multiplied by 6 meters separation) while the total length of the tomography was planned to reach close to 1200 meters.

So, the method of roll along tomographies has been applied and supplementary tomographies have been added to the initial one. The layout of the design of the following the initial one tomography is described in Fig. 4b.

The Tsourlos (1995) algorithm for the inversion of the data has been used in addition with the RES2DINV program (Li and Oldenburg 1992). 
Topography has been taken under consideration in order to get the realistic resistivity distribution in the area.

\subsection{VLF electromagnetic method.}

The WADI (ABEM Instruments) instrument has been used in order to measure the tilt angle and ellipsicity of the magnetic component of the electromagnetic field.

VLF method is widely used for the detection of conductive zones that reflect the existence of fault structures/zones filled with material as clay or water.

Secondary electromagnetic field produced by a primary one propagating in conductive zones is measured and enable us to detect the source.

Raw data which refer to the real (tilt) and imaginary (ellipsicity) component of the magnetic field are processed further in order to be interpreted. Fraser filter has been applied in the first place while Karous-Hjelt filter has also been applied.

Sector software (ABEM Instruments) as well as the Nissen's (1986) program have been used.

The first one permits the qualitative interpretation of the data since Nissen's code allows the characterization of the fault zones as concern their resistivity. Thus, more accurate interpretation as concern the material that fills the faults is achieved.

\section{Field survey-Interpretation}

The location of electrical tomography and VLF profiles that have been conducted are presented in Fig. 6.

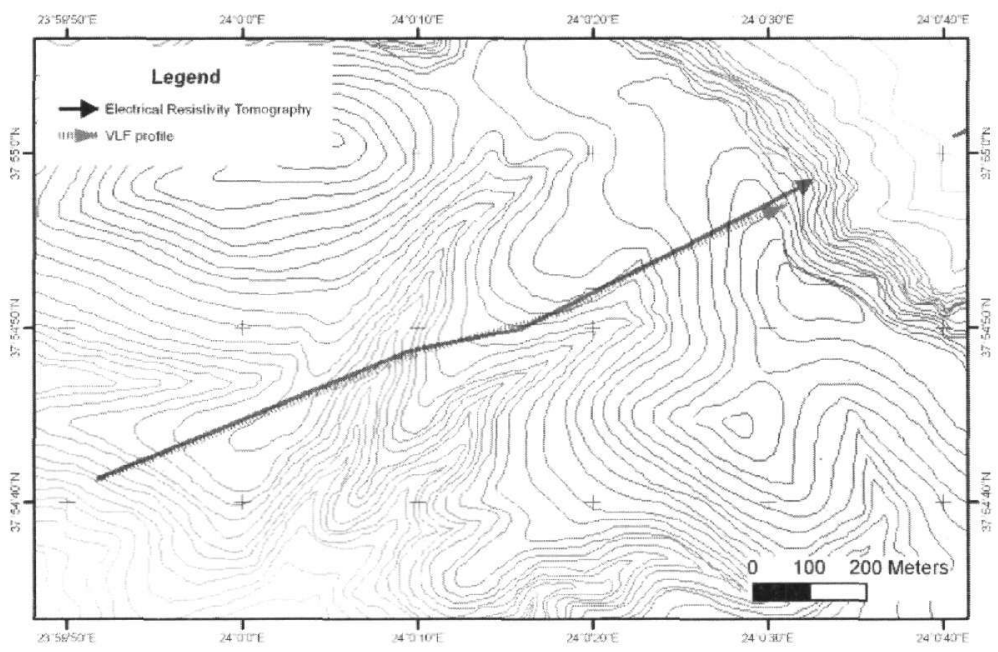

Figure 5 - Location of the tomography and VLF profile

\subsection{Electrical tomography}

In order to complete the tomography ten (10) roll along tomographies after the initial one have been conducted. Roll along tomographies were using 33 overlapped electrodes in order to record the supplementary data set. The final length of the tomography was 1176 meters. Since morphology did not allow the completeness of the tomography to the northern exit of the tunnel, a supplementary separated tomography has been measured at that area.

Raw data, inversion model and final resistivity model of the first part of the tomography are presented in Figure 6. 


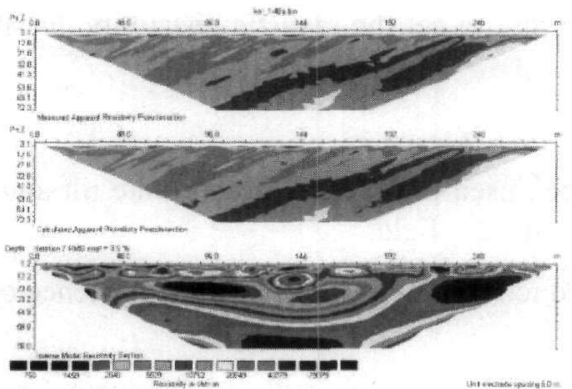

a

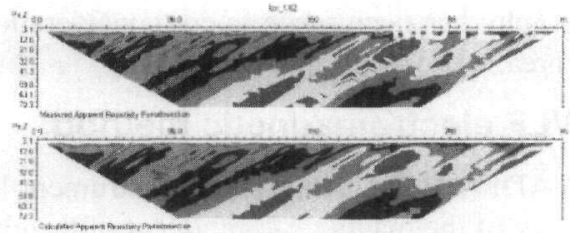

C

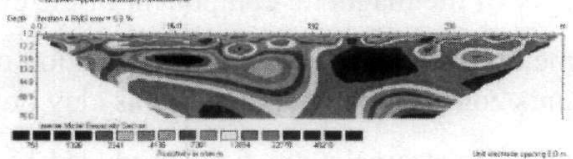

Figure 6 - First array (on the left) plus first roll along (at the right)

Each image contains three parts. In the upper part (Fig. 6a) the raw data are drawn. In the middle one (Fig. 6b), the initial inversion model is represented and at the bottom, the final resistivity model is shown (Fig. 6c).

In the left figure the first profile is represented. In the right someone can see the initial one where the data of the first roll along have been added and as result we get a tomography of 62 electrodes.

That procedure has been applied for the rest of the tomography till the maximum length has been achieved.

The complete tomography is represented to Fig. 7.
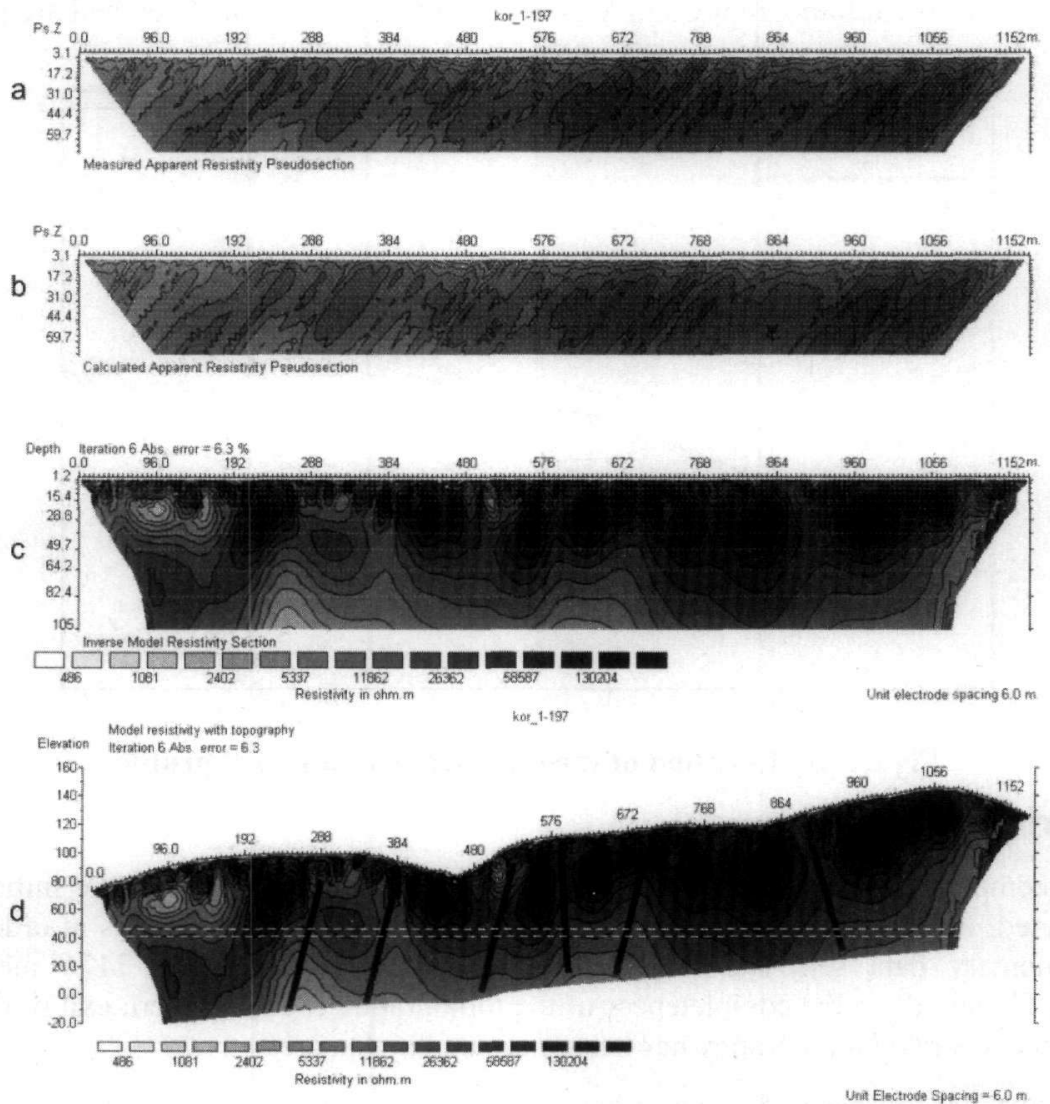

Figure 7 - Inversion of complete tomography 
In the next step the data have been inverted with the topography included.

Fig. $7 \mathrm{~d}$ represents the $2 \mathrm{D}$ resistivity profile of the underground at the approximate depth of $105 \mathrm{~m}$. while dashed line shows the location of the tunnel that is going to be constructed.

From the data we can suppose that only a geological unit, limestone, is present in the depth investigated by tomography (about $100 \mathrm{~m})$. The superficial zone $(0-50 \mathrm{~m})$ does not appear homogeneous since resistivity changes are observed in lateral and vertical directions. First 15 meters look to be formed by very inhomogeneous material, a fact that probably represents the karstic-weathered zone.

Less resistive zones are between 288 and $384 \mathrm{~m}$., $500 \mathrm{~m}$., $580 \mathrm{~m}$. and finally close to $900 \mathrm{~m}$. These zones may are related with fault zones at the area.

Below the depth of 60 meters it looks to become less resistive. That could be an indication of the location of the water level.

\subsection{VLF measurements.}

A VLF profile has been measured along the tomography in a sampling interval of 10 meters. The aim of the VLF survey was to locate the conductive zones in parallel with the resistivity tomography in order to give further information about fault systems/zones since it is very sensitive to lateral resistivity changes.

Raw data have been interpreted by the application of Fraser and Carous-Hjelt filters. The application of Nissen's program allowed the application of topography correction to the data. In addition the quantitative estimation of the resistivity of the conductive zones by VLF measurements was achieved.

Real and imaginary raw VLF data are represented in Fig. 10.

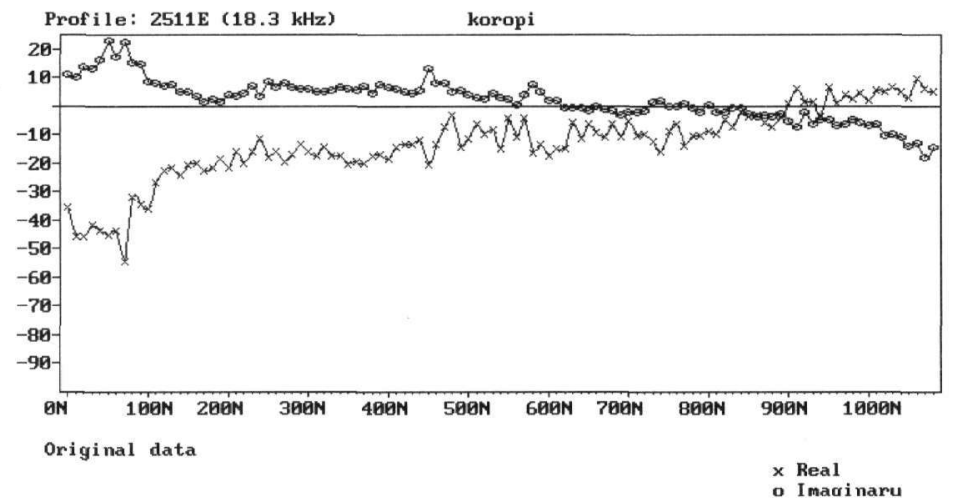

Figure 8 - Raw data of VLF measurements after the topography correction

Conductive zones related to tectonic features in raw data can be observed in areas where Real component crosses the Imaginary one or in areas where Real component changes sign even it does not cross the imaginary component. In general that is difficult to be clearly observed. That is why the application of filters is needed.

The result of the application of Fraser filter is represented in Fig. 9.

In figure 9 the conductive zones are represented with positive anomalies while negative anomalies show areas where the resistivity of the geological formations is higher than the environment.

Observed anomalies are located to the 300,560 and $710 \mathrm{~m}$. distances from the beginning of the profile. 


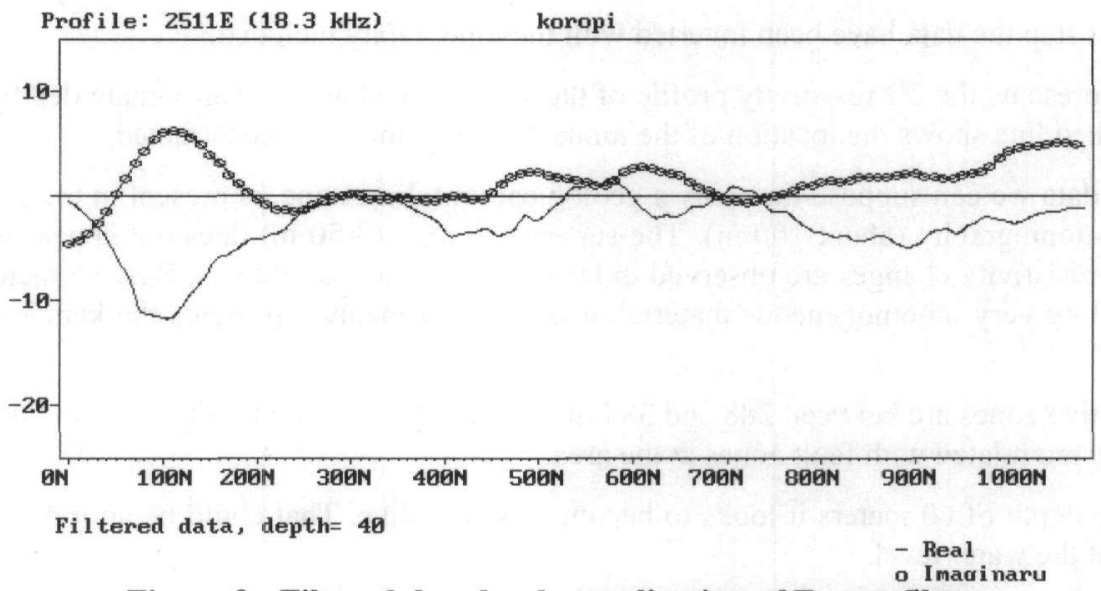

Figure 9 - Filtered data by the application of Fraser filter

Nissen's program (VLFMOD) allowed the more accurate location of the conductive zones as concern the positioning and the inclination in addition with the estimation of their resistivity.

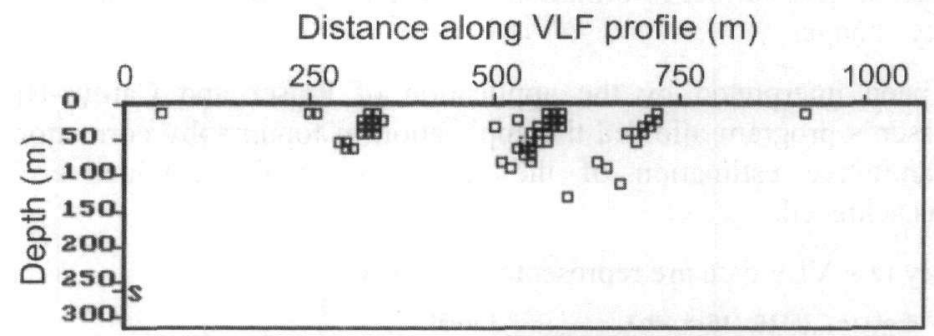

Figure 10 - Conductive bodies estimated by VLFMOD

Someone can see groups of small squares composing the conductive zones. The general inclination of the faults is towards the south and their resistivity varies from 25 to $100 \mathrm{Ohm}-\mathrm{m}$ considering tha $\mathrm{t}$ the resistivity of halfspace is close to $5000 \mathrm{Ohm}-\mathrm{m}$. The resistivity is believed that it varies in acc ordance with the filling material of the faults that could be either water of red clay.

\section{Conclusion}

In the present study the application of electrical tomography and VLF method to the construction of a tunnel is discussed. Geophysical methods were applied to give more detailed information as concern the nature and the characteristic behaviour of the geological formations that were to be drilled.

In the following figure someone can see the total information of the area surveyed and the results. The figure above shows that the conductive zones revealed by the VLF method are in a very good agreement with the conductive zones of the electrical tomography.

In the same figure the predicted location of the tunnel is shown. It is clear that geophysical results can give important information as concern the drilling of the tunnel. Someone can see the positions where hard compact rock can be expected (high resistivity areas) since areas showing low resistivity are expected to be faulted. That means that these low resistivity zones are expected to be looser and contain groundwater.

Results are in a very good agreement with the geological observations since, the geological mapping of the area describes faults having slopes dip similar to the ones predicted by the geophysical survey. 

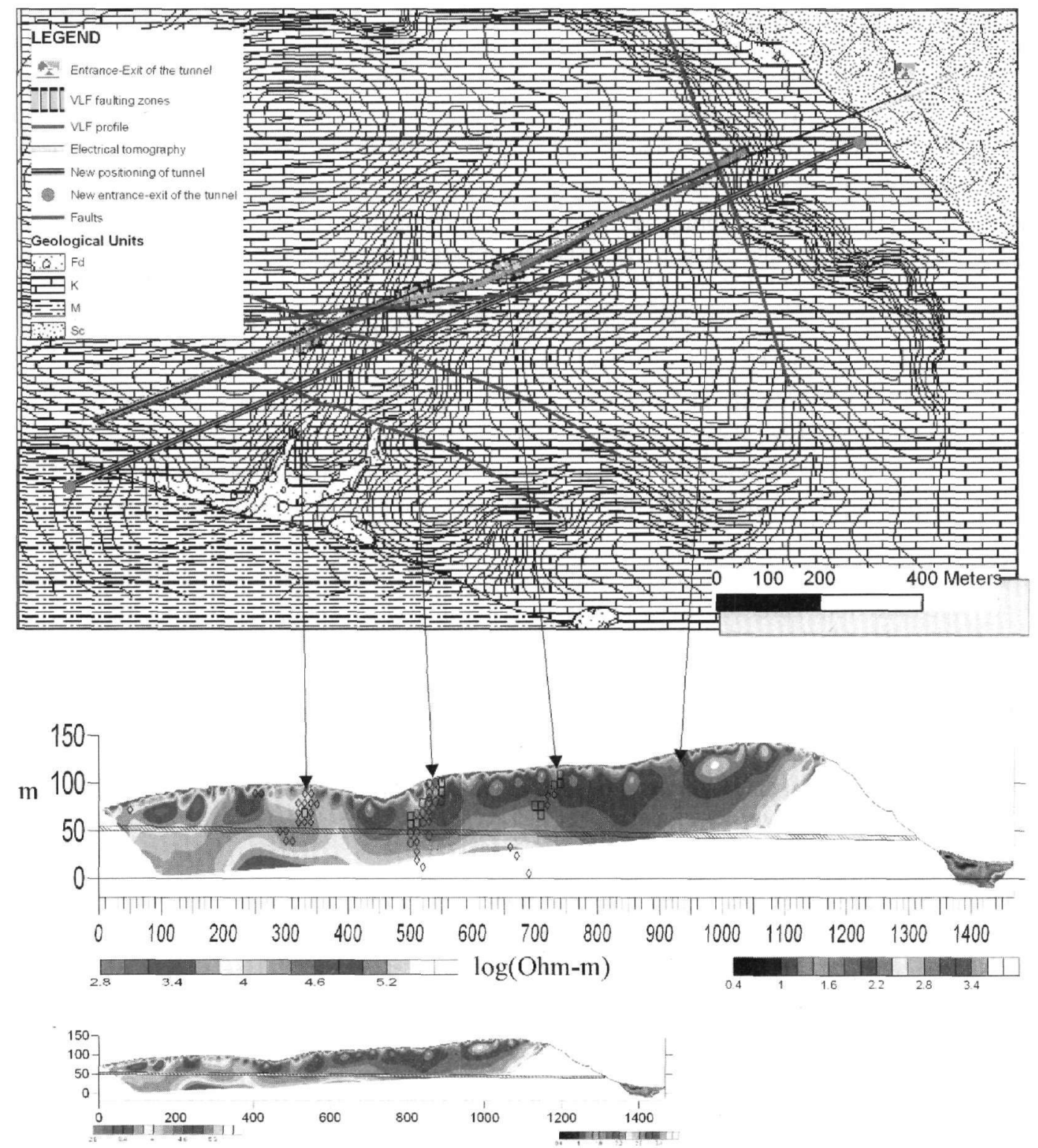

Figure 11 - Results of geophysical survey. Resistivity scale is logarithmic

This information is useful since direct survey (i.e. drilling program) can be scheduled more accurately since geophysical investigation allows the further study of zones that are more interesting to be studied.

\section{Acknowledgments}

We would like to thank the Municipality of Kropia which had the initiative and financed the project giving the possibility of collecting the data.

We would like also to thank both reviewers for the attentive reading and the suggestions that they made and which have been taken into account in the final revision of the manuscript. 


\section{References}

Cardarelli, E., Marrone, C., and Orlando, L., 2003. Evaluation of tunnel stability using intergrated geophysical methods, Journal of Applied Geophysics, 52, 93-102.

Cosenza, P., Marmet, E., Rejiba, F., Jun Cui, Y., Tabbagh, A., and Charlery, Y., 2006. Correlations between geotechnical and electrical data: A case study at Garchy in France, Journal of Applied Geophysics, 60, 165-178.

Friedel, S., Thielen, A., and Springman, S.M., 2006. Investigation of a slope endangered by rainfall-induced landslides using 3D resistivity tomography and geotechnical testing, Journal of Applied Geophysics, 60, 100-114.

Li, Y., and Oldenburg, D.W., 1992. Approximate inverse mappings in DC resistivity problems. Geophysical Journal International, 109, 343-362.

Nissen, J., 1986. A versatile electromagnetic modeling program for 2-D structures, Geophys. Prospect., 34, 1099-1110.

Rey, E., Jongmans, D., Gotteland, P., and Garambois, S., 2005. Characterisation of soils with stony inclusions using geoelectrical measurements, Journal of Applied Geophysics, 58, 88201.

Roth, M.J.S., Mackey, J.R., Mackey, C., and Nyquist, J.E., 2002. A case study of the reliability of multielectrode earth resistivity testing for geotechnical investigations in karst terrains, Engineering Geology, 65, 225-232

Sultan, S.,A, Helal, A., and Santos, F.A.M., 2004. Geoelectrical application for solving geotechnical problems at two localities in Greater Cairo, Egypt, NRIAG Journal of Geophysics, 3(1), 51-64.

Tsourlos, P., 1995. Modeling interpretation and inversion of multielectrode resistivity survey data. Ph.D. Thesis, University of York. 